\title{
Mercado laboral de egresados de la Licenciatura en Geografía de la Universidad Autónoma de Guerrero y de Geoinformática de la Universidad Autónoma de Ciudad Juárez
}

\section{Labor market of graduates of the Geography Degree of the Universidad Autónoma de Guerrero and Geoinformatics of the Universidad Autónoma de Ciudad Juárez}

\author{
Adrián Urióstegui Flores \\ Universidad Autónoma de Guerrero, México \\ a_uriostegui@yahoo.com \\ (D) http:/ / orcid.org/0000-0002-9154-3195 \\ Alma Villaseñor Franco \\ Universidad Autónoma de Guerrero, México \\ alvif27@yahoo.com.mx \\ (D) http://orcid.org/0000-0001-6748-9662 \\ Luis Carlos Bravo Peña \\ Universidad Autónoma de Ciudad Juárez, México \\ luis.bravo@uacj.mx \\ (D) http://orcid.org/0000-0002-9825-3940
}

Recepción: 23 de octubre de 2018

Aprobación: 14 de mayo de 2019

(c) $(\$)$

(c) $\mathrm{BY}$ NC ND

\begin{abstract}
RESUMEN
Se analiza el mercado laboral de egresados de la Licenciatura en Geografía de la Universidad Autónoma de Guerrero, y de la Licenciatura en Geoinformática de la Unidad Multidisciplinaria de la Universidad Autónoma de Ciudad Juárez, ambas de México. Se encuestó un total de 94 egresados en el año 2017 y se entrevistó a siete informantes clave. Entre los hallazgos importantes destaca el tipo de institución y/o empresa empleadora, la ciudad y estado donde se encontraban trabajando, los tipos de puestos, las actividades realizadas, el salario mensual percibido, y las sugerencias para mejorar las carreras.
\end{abstract}

Palabras Clave: mercado laboral, educación superior, geografía, geoinformática.

\section{Abstract}

This paper analyzes the job market of graduates of the Bachelor's Degree in Geography of the Universidad Autónoma de Guerrero, and of the Degree in Geoinformatics of the Unidad Multidisciplinaria de la Universidad Autónoma de Ciudad Juárez, in México. A total of 94 graduates were surveyed in 2017. In addition, seven key informants (experts, specialists and teachers) were interviewed. Among the important findings, we highlighted the type of institution and/or employer, the city and state where they were working, the types of positions, the activities carried out, the monthly salary received, and suggestions to improve careers.

KEYWORDS: Job market, higher education, geography, geoinformatics.

\section{INTRODUCCIÓN}

Este artículo tiene como principal objetivo analizar el mercado laboral de egresados de la Licenciatura en Geografía de la Universidad Autónoma de Guerrero ubicada en Taxco el Viejo, Guerrero, y de la Licenciatura en Geoinformática de la Unidad Multidisciplinaria de la Universidad Autónoma de Ciudad Juárez, localizada en Ciudad Cuauhtémoc, Chihuahua, México. 
Se encuestó a un total de 94 egresados en 2017 (78 egresados de geografía y 16 de geoinformática) y se entrevistó a siete informantes clave (expertos, especialistas y docentes). Ambas profesiones son de creación reciente; la licenciatura en geografía tuvo sus inicios en 2008, mientras que la de geoinformática empezó sus actividades académicas a partir de 2010.

\section{Postura y antecedentes}

Este artículo se encuentra enmarcado en el área de geografía y del mercado laboral. Al respecto, se tomó en cuenta la propuesta teórico-metodológica denominada “estudios de opiniones de egresados y empleadores” (Gómez citado por Magaña, 2007). La contribución de este trabajo consiste en el análisis de los datos empíricos y la explicación del panorama del mercado para dichas carreras.

En la revisión bibliográfica se confirmó la escasez de trabajos académicos en México que han abordado la temática de mercado para las dos profesiones referidas. Estudios recientes de Checa (2014) corroboran que las propuestas sobre empleo para el área de geografía son muy limitados:

Los análisis de empleabilidad hechos desde las diversas licenciaturas de geografía en México son todavía escasos, tanto actuales como los realizados con cierta clave histórica [...]. En otros casos, ni tan sólo se ha realizado un mínimo estudio de empleabilidad, ya sea por lo recién de la creación de la licenciatura, ya sea por falta de recursos o por desinterés por el tema de los cuadros docentes (Checa, 2014: 8-19).

Dentro del acotado panorama del artículo destacan las propuestas de a) Amaro et al. (2010), en donde se analiza la opinión de los empleadores de los egresados de la Licenciatura en Geografía de la Universidad de Guadalajara, b) las obras de Amezcua et al. (2010) relacionadas con un diagnóstico de egresados de la licenciatura en geografía, c) los informes de Franco (2008) referentes al plan de desarrollo de la Facultad de Geografía de la Universidad Autónoma del Estado de México, d) los escritos de Urióstegui (1995) que abordan el tema de seguimiento de egresados y mercado laboral para la Licenciatura en Geografía de la Universidad Autónoma del Estado de México y e), las propuestas de Castañeda (2006) que detallan el recorrido histórico sobre la enseñanza de la geografía en México, los contenidos geográficos y los métodos de enseñanza, por citar algunos ejemplos.

En este sentido, de los pocos trabajos que destacan, y específicamente para el caso de la carrera de geografía ofertada en la Universidad Nacional Autónoma de México (UNAM), se encuentra el de Chías et al. (1994), el cual menciona las graves problemáticas relacionadas con el mercado de trabajo suscitadas en los setenta y ochenta:

El problema nace prácticamente durante los años setenta cuando el explosivo crecimiento de la población estudiantil rebasó la demanda real del mercado de trabajo y se agravó en los ochenta al saturarse el ámbito de trabajo docente y no poder insertarse en otros oficios por las características que prevalecen en el perfil académico del geógrafo: formación básicamente escolar alejada de la realidad nacional y fundamentalmente retrospectiva y no prospectiva (Chías et al., 1994: 80).

Dentro de los trabajos mencionados, vale la pena destacar el análisis de las competencias profesionales del licenciado en geografía en México realizados por Checa (2013), y el estudio del mercado laboral en México desde la perspectiva de geografía de género donde se analizan las tasas de desempleo abierto por género y regiones económicas de 1995 a 2001 (Escamilla y Santos, s/f).

Asimismo, en obras de Urióstegui (1996) se han explicado los resultados obtenidos de entrevistas realizadas a personal de administración de 26 diferentes instituciones de ocupación del profesionista en geografía en la ciudad de Toluca, Estado de México. Aquí resalta sobre todo la demanda de los sectores requeridos, las prestaciones ofrecidas, el sueldo inicial y las posibilidades de desarrollo profesional, entre otras variables.

Para el caso de la Licenciatura en Geografía que se oferta en la Universidad Autónoma del Estado de Guerrero, ya en escritos de Urióstegui (2011) se han explorado de manera concreta algunas de las características de los 
puestos solicitados en instituciones de gobierno, empresas privadas y docencia para el egresado de dicha carrera. Lo anterior incluyó cuestiones tales como el tipo de institución y/o empresa empleadora, el lugar donde se ofertaba la vacante, la denominación del puesto, la escolaridad y/o experiencia solicitada, y el sueldo ofrecido.

De igual manera, en Urióstegui (2011) se llegan a explicar algunas de las problemáticas que condicionaron (directa o indirectamente) el acceso al mercado para los egresados de la Licenciatura en Geografía de la Universidad Autónoma del Estado de México. Lo anterior en especial para el periodo que abarcó el segundo lustro de los ochenta y la década de los noventa.

Entre estas problemáticas destaca la limitada relación que existía entre los conocimientos teóricos adquiridos en la carrera y los requerimientos prácticos que se pedían en las empresas, la saturación de vacantes debido al exceso de la matrícula de egreso, la deficiente formación escolar de los alumnos, la carencia de vocación para enseñar por parte de los educadores (en ciertas áreas técnicas, básicas y de especialización), la falta de actualización que el personal docente presentaba respecto a innovaciones tecnológicas, la lucha de grupos internos por el control político y de cargos, el desconocimiento profundo respecto a técnicas pedagógicas por parte de profesores, el empleo de material bibliográfico obsoleto, el contrato de educadores sólo por hora-clase y el consecuente bajo salario percibido, el compadrazgo para la elección de educadores, el limitado grado académico solicitado para la contratación de algunos de estos profesores (sin posgrado), o bien, la retraída comunicación que el personal administrativo mantuvo con las empresas de ocupación, por citar algunos inconvenientes.

Para el caso de la Licenciatura en Geografía que se imparte en la Unidad Académica de Ciencias de la Tierra de la Universidad Autónoma de Guerrero también se han confirmado diversos inconvenientes que han impactado de forma negativa (también directa e indirectamente) en cuestiones de mercado y empleo de egresados (comunicación personal con informantes anónimos, 2018).

Entre las limitantes más sobresalientes se encuentran a) la falta de apoyo por parte de administrativos locales para fomentar la vinculación entre dependencias y empresas que emplean al profesionista (situación que ha incluido el desinterés por difundir las convocatorias laborales correspondientes), $b$ ) el nulo respaldo para la bolsa de trabajo, c) la indiferencia para incorporar la licenciatura a la red nacional de escuelas de geografía, $d$ ) la insuficiente exigencia que se tiene con educadores que no se han titulado del grado de maestría o doctorado, $e$ ) la carencia de producción en cuanto a publicaciones por parte de un grupo específico de maestros, $f$ ) los conflictos y la lucha por el poder entre grupos al interior de la unidad, $g$ ) el despido injustificado, acoso e intimidación hacia docentes por diferencias políticas y/o personales (los docentes despedidos incluso contaban con posgrados realizados en Europa, o eran miembros del Sistema Nacional de Investigadores del CONACYT) o b), el contrato de educadores por compadrazgo y/o servilismo político (y que no contaban con el título de maestría), por mencionar sólo algunas ideas (comunicación personal con informantes anónimos, 2018).

Las dos carreras en cuestión también presentan obstáculos similares a las ya observadas por Escamilla et al. (2015) en obras que abordan la situación de empleo para la Región Centro de México y la evolución del comportamiento laboral. En este caso destaca específicamente cómo no se han alcanzado a cubrir los puestos de trabajo:

\footnotetext{
Aquí se muestra cómo en una de las regiones económicas más dinámicas del país, la Región Centro de México, que a pesar de aglutinar más de 12 zonas metropolitanas y otras ciudades medias y pequeñas no se alcanzan a cubrir los puestos de trabajo tanto para las nuevas generaciones que terminan su formación educativa técnica o profesional como a los que por diversas circunstancias son separados de sus trabajos por cierre de fábricas, negocios o empresas y pasan a engrosar las filas del desempleo, subempleo y/o autoempleo, en el mejor de los casos, sino es que son forzados a integrarse a la delincuencia organizada deteriorando la calidad de vida de la población (Escamilla et al., 2015: 1-2).
}

Otras dificultades que también se sugiere sean analizadas por el personal administrativo de las dos carreras son las referidas por Burgos y López (2010) en publicaciones que abordan el empleo de profesionistas de la Universidad de Sonora: 
Una proporción importante de ellos no obtiene remuneraciones adecuadas, se desempeña en puestos de carácter no profesional, ocupa un puesto para el cual no se requería de estudios de nivel superior, el empleo que desarrolla no tiene mucha coincidencia con la carrera estudiada y no aplica plenamente los conocimientos y habilidades adquiridos en la universidad (Burgos y López, 2010: 31).

A grandes rasgos, de los pocos escritos elaborados para la profesión de geoinformática destaca un seguimiento de egresados realizado por la Universidad Autónoma de Ciudad Juárez (Universidad Autónoma de Ciudad Juárez-Dirección General de Planeación y Desarrollo Institucional, 2017), así como un estudio de empleadores (Universidad Autónoma de Ciudad Juárez-Dirección General de Planeación y Desarrollo Institucional, 2016).

\section{Metodología}

El estudio fue mixto, de tipo cualitativo y cuantitativo. Para el aspecto cualitativo se utilizó el muestreo por conveniencia (Hernández et al., 2010) y se encuestó a un total de 94 egresados (78 de geografía y 16 de geoinformática). El cuestionario de encuesta incluyó 20 preguntas abiertas y cerradas. Asimismo, se entrevistó a siete informantes clave (expertos, especialistas y docentes) de las licenciaturas en cuestión respetando el respectivo anonimato.

La encuesta se aplicó en noviembre de 2017 a egresados de la Licenciatura en Geografía de la Universidad Autónoma de Guerrero, en Taxco el Viejo, Guerrero, así como a egresados de la Licenciatura en Geoinformática de la Universidad Autónoma de Ciudad Juárez, en Ciudad Cuauhtémoc, Chihuahua, México. Para el aspecto cuantitativo se empleó la estadística descriptiva. Se aclara que el trabajo es de tipo cuantitativo no probabilístico.

Las 20 variables del cuestionario de encuesta a medir fueron $a$ ) lugar de nacimiento, $b$ ) sexo, $c$ ) edad, $d$ ) año de ingreso y egreso en la carrera, $e$ ) contar o no con empleo actualmente (o sin empleo y realizando tesis, o en otra actividad diferente a la carrera), $f$ ) ciudad y estado donde se labora (incluyendo el nombre y tipo de institución), $g$ ) tipo de puesto que se desempeña, $h$ ) las actividades realizadas, $i$ ) la forma de obtención del trabajo, $j$ ) antigüedad, $k$ ) el número de dependencias visitadas y solicitudes hechas antes de la primera contratación, $l$ ) salario mensual, $m$ ) tipo de prestaciones, $n$ ) tipo de contrato, $\tilde{n}$ ) grado de satisfacción con las actividades desarrolladas, $o$ ) la compatibilidad de los conocimientos y técnicas aprendidas en su carrera con la actividad de su trabajo, $p$ ) los campos o técnicas específicas que aplicaba en su empleo, $q$ ) las áreas o rubros que se consideraba deben reforzase o incluirse para que los alumnos encuentren ocupación más fácilmente, r) las sugerencias para mejorar la carrera y $s$ ) las propuestas que se tenían para que el recién egresado pudiera encontrar un cargo a la menor brevedad.

En otro aspecto, se contactó básicamente a los egresados de manera personal, por medio de profesores, compañeros de profesión y/o alumnos, así como por correo electrónico y teléfono. Como aclaración, se encuestó en particular a los profesionistas que pudieron localizarse. Entre las dificultades por las que no fue posible encontrarlos se debieron a que habían cambiado de residencia, las direcciones no se encontraban actualizadas, habían modificado los datos de contacto, o no fue posible ubicarlos por medios electrónicos o telefónicos.

Adicionalmente, se explican los principales postulados teóricos del plan de estudios de la licenciatura en geografía, y se analizan las áreas y especialidades en las cuales se encontraban laborando los egresados encuestados (tema que se desarrolla en el apartado de Discusión).

Vale la pena mencionar que, de acuerdo con datos recientes, para 2018 la matrícula total de la carrera de geografía era de 83 alumnos, los cuales se encontraban repartidos en cuatro diferentes semestres (segundo, cuarto, sexto y octavo semestre) (Universidad Autónoma de Guerrero, 2018). La Licenciatura en Geoinformática contaba con 98 
estudiantes para 2017, los cuales estaban organizados en cuatro semestres según los datos proporcionados por la Universidad Autónoma de Ciudad Juárez (2017).

\section{Resultados}

\section{1. Mercado laboral de los egresados de la Licenciatura en Geografía de la Universidad Autónoma de Guerrero}

Para el caso de la Licenciatura en Geografía de la Universidad Autónoma de Guerrero, 78 egresados (100\%) contestaron la encuesta. De ellos, 37\% (29 casos) trabajaba en áreas afines a la geografía, mientras que 14\% (11 casos) expresó laborar en otras áreas diferentes a su carrera. De los resultados encontrados, destaca el alto porcentaje de desempleados, ya que 26\% (20 casos) confirmó estar en dicha condición (gráfica 1).

También se aclara que 6\% ( 5 casos) dejaron el cuestionario incompleto y/o no contestaron; manifestaron no tener disposición, ningún interés, empeño, tiempo o porque "se preguntaban cosas muy personales".

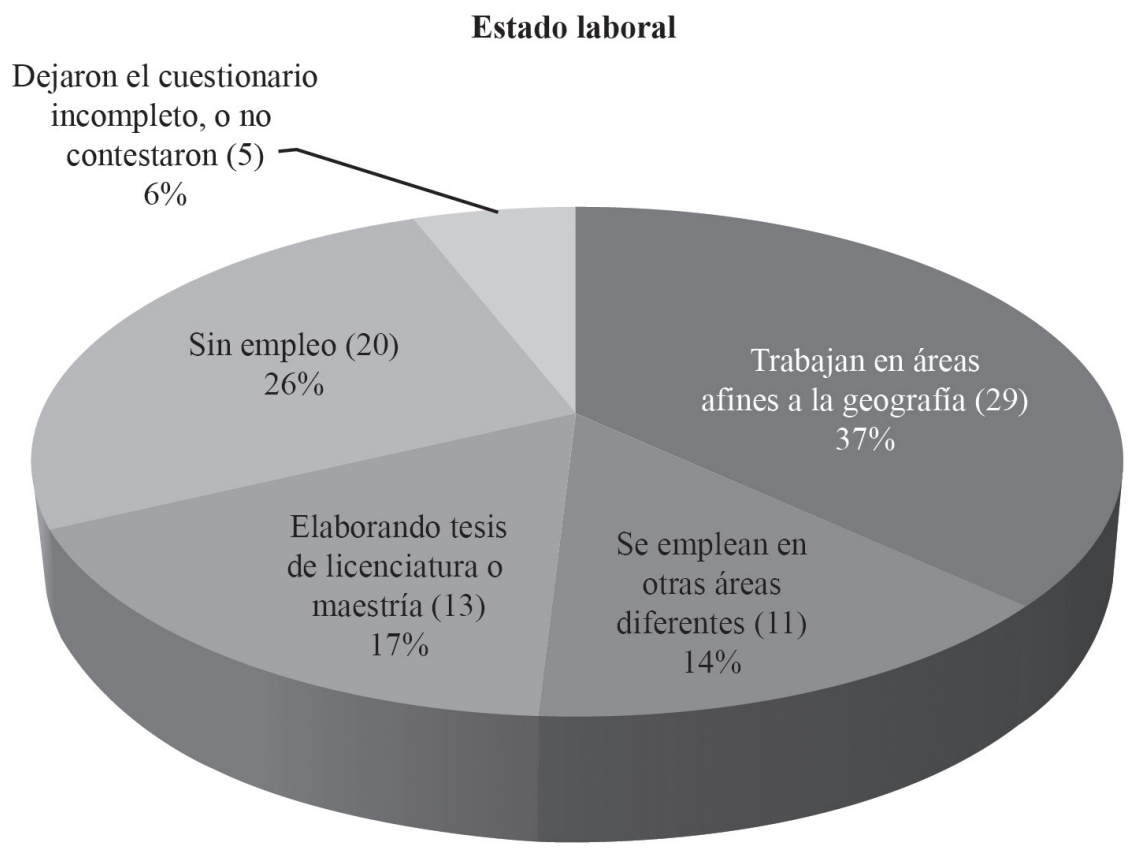

\section{GRÁFICA 1}

Total de egresados que trabajan en áreas afines o no a la geografía, así como total de desempleados, 2017 Fuente: elaboración propia, 2018. Nota: número total de egresados encuestados: 78 (100\%).

Como se mencionó con anterioridad, 37\% (29 casos) de los egresados se encontraba trabajando en áreas afines a la geografía. Los nombres de las dependencias, empresas y escuelas que contrataron a dichos profesionistas, lugares donde laboraban, tipos de puesto, actividades realizadas y salario pueden observarse con mayor detalle en el anexo A.

Básicamente, se encontraban en ciudades y estados cercanos tales como Cuernavaca (Morelos), Taxco, Iguala y/o Chilpancingo (Guerrero) y Ciudad de México, así como también en ciudades más alejadas como Querétaro (Querétaro), Fresnillo (Zacatecas), Guadalajara (Jalisco) y Puebla (Puebla).

El salario mensual osciló entre un máximo de $\$ 21000.00$ pesos mensuales y un mínimo $\$ 2000.00$ pesos mensuales. 
Sobre los egresados que trabajaban en ocupaciones diferentes a la geografía, los salarios estuvieron desde $\$ 6$ 000.00 pesos mensuales hasta $\$ 600.00$ pesos mensuales (tabla 1 ), aquí la mayoría se encontraban en las ciudades de Iguala y Taxco (Guerrero), Yecaplixtla (Morelos) y Querétaro (Querétaro).

TABLA 1

Características laborales de egresados que trabajan en áreas diferentes a la geografía, 2017

\begin{tabular}{|c|c|c|c|c|}
\hline Institución y/o empresa* & Ciudad y estado & Puesto & Actividad & $\begin{array}{l}\text { Salario mensual (en } \\
\text { pesos mexicanos) }\end{array}$ \\
\hline Aurrerá, Chedraui & Taxco, Guerrero & Empleado & Promotor & $\$ 6000.00$ \\
\hline $\begin{array}{l}\text { Incubadora Agrícola El } \\
\text { Peñón }\end{array}$ & Yecapixtla, Morelos & Empleado & $\begin{array}{l}\text { Encargado de turno, revisión } \\
\text { de máquinas, ovoscopia, } \\
\text { desinfección }\end{array}$ & $\$ 6000.00$ \\
\hline $\begin{array}{l}\text { Ayuntamiento de Taxco } \\
\text { de Alarcón }\end{array}$ & Taxco, Guerrero & Profesor & Clases de alfabetización & $\$ 5500.00$ \\
\hline $\begin{array}{l}\text { Instituto de Seguridad y } \\
\text { Servicios Sociales de los } \\
\text { Trabajadores del Estado } \\
\text { (ISSSTE) }\end{array}$ & Iguala, Guerrero & Empleado & $\begin{array}{l}\text { Actividades variables de } \\
\text { acuerdo con el departamento } \\
\text { donde se trabaje }\end{array}$ & $\begin{array}{l}\text { De } \$ 2400.00 \\
\text { a } \$ 5000.00\end{array}$ \\
\hline $\begin{array}{l}\text { Negocio por cuenta } \\
\text { propia (computación) }\end{array}$ & Taxco, Guerrero & $\begin{array}{l}\text { Negocio por } \\
\text { cuenta propia }\end{array}$ & Reparación de computadoras & $\$ 2000.00$ \\
\hline $\begin{array}{l}\text { Trabajo por cuenta } \\
\text { propia (platería) }\end{array}$ & Taxco, Guerrero & Platería & Actividades de platería & $\$ 600.00$ \\
\hline Estudio de fotografía & Taxco, Guerrero & Empleado & Actividades de fotografía & No contestó \\
\hline Coppel & Taxco, Guerrero & Empleado & $\begin{array}{l}\text { Atención a clientes, venta de } \\
\text { productos }\end{array}$ & No contestó \\
\hline $\begin{array}{l}\text { Trabajo por cuenta } \\
\text { propia }\end{array}$ & Taxco, Guerrero & $\begin{array}{l}\text { Trabajo por } \\
\text { cuenta propia }\end{array}$ & Venta de ropa & No contestó \\
\hline Escuela privada & Querétaro, Querétaro & Secretaria & Administración & No contestó \\
\hline Bancomer & Taxco, Guerrero & Empleada & Cajera & No contestó \\
\hline
\end{tabular}

Fuente: elaboración propia, 2018.

Respecto a las áreas que se consideran deben reforzarse o incluirse en la carrera para que sea posible encontrar empleo más fácilmente, resalta la necesidad de abrir una materia pedagógica para ejercer en el ámbito docente, crear estrategias de aprendizaje para conocer en dónde se puede laborar, adaptar programas más potentes que soporten los sistemas operativos de SIG, integrar las áreas de estudio con los mismos SIG, implementar nuevas tecnologías en computación, incrementar la cantidad de docentes con doctorado para las distintas ramas, elaborar proyectos en áreas geográficas o geológicas en dependencias que actualmente apoyan con recursos, utilizar los SIG en las salidas de campo, actualizar la información con la cual se preparan las clases y los programas de SIG, incluir el procesamiento de imágenes satelitales, enseñar bases de datos, profundizar en el análisis 3D de zonas y perfiles, emplear en mayor medida los GPS y las herramientas para campo e inclusive, incrementar el número de clases. 
También se sugirió reforzar el contenido de diversas materias como cartografía, geografía rural, geografía urbana, geografía de los servicios, percepción remota, geología de campo y estructural, hidrología, geografía de los riesgos, climatología, biología, biogeografía, geografía humana, geografía del turismo, vulnerabilidad, geografía agropecuaria, geomorfología, ordenamiento territorial, geografía del desarrollo, geografía de campo 2 , planeación, geografía política, geografía cultural, geografía de la población, geografía económica y estadística, así como vincular la geografía física con la geografía humana.

Sobre las sugerencias para renovar la carrera resaltó la necesidad de actualizar los programas de SIG, utilizar nuevas tácticas de aprendizaje, mejorar el inglés y la ortografía, emplear nuevas metodologías de aprendizaje, orientar al alumno sobre los campos de la geografía que puede elegir, conseguir bases para los maestros, establecer vínculos con organizaciones para que conozcan la carrera y pueda ser más fácil la contratación, hacer prácticas profesionales con mayor tiempo de duración, definir los sectores físico y social debido a que faltan materias en este último ámbito, aumentar la planta docente, conseguir un mejor equipo para los laboratorios de SIG, fortalecer el enfoque geográfico con otras disciplinas que se imparten, difundir las áreas donde es posible trabajar, integrar en mayor medida las ramas de la especialidad, buscar una mayor preparación en la enseñanza, vincular de mejor manera las prácticas profesionales con el desempeño profesional, organizar las clases de acuerdo con el campo de cada profesor, preparación individual del alumno para que adquiera independencia y disciplina de trabajo en equipo, así como la contratación de maestros del área de geografía.

En este sentido, se considera necesario ofertar cursos extras o propedéuticos antes de ingresar a la carrera, mejorar la infraestructura, promover en mayor medida la licenciatura, incluir conferencias y talleres sobre las distintas ramas de la carrera por parte de académicos externos de diferentes instituciones del país, actualizar los conocimientos de docentes, renovar aulas y laboratorios, se consideró que lo teórico no funcionaba mucho en lo laboral, por ello se requiere reforzar técnicas para adquirir experiencia, crear los laboratorios de edafología y biogeografía, reformar el plan de estudios debido a que los objetivos ya habían quedado obsoletos y los contenidos no concordaban con los problemas actuales, anexar otras materias (como geomarketing, impacto ambiental, geografía de la salud, geografía de la violencia, geografía social con estudios de violencia o catastro), obtención del título y la cédula, difundir las habilidades del geógrafo en empresas privadas y de gobierno, orientar al alumno sobre sus respectivas áreas de trabajo antes de egresar, aprender temas de negocios y economía, evaluar a los alumnos con un examen general antes de culminar sus estudios y discernir sí tienen los conocimientos necesarios ( si no los tienen no permitir su salida), evaluar y acreditar la licenciatura, o bien, reforzar las asignaturas de geografía humana.

Asimismo, se sugirió conseguir convenios con empresas públicas y privadas para que los alumnos realicen servicio social y prácticas profesionales (como Catastro, SAGARPA, SEDESOL o INEGI), difundir las características de la carrera (incluyendo visión, misión y campo laboral), tomar en cuenta las experiencias de algunos alumnos egresados, mejorar las condiciones del laboratorio de geomática con equipos que soporten los programas (ya que no funcionan de manera adecuada), adquirir conocimientos externos a los enseñados en la universidad y en los ramos de otras ciencias, anotar otras habilidades adquiridas en el curriculum vitae (CV) para lograr mayor oportunidad, incrementar la bibliografía relacionada con la carrera, desarrollar las clases de acuerdo con lo estipulado en el plan de estudio respecto a la teoría y campo, o tomar en cuenta nuevas tecnologías de SIG y percepción remota.

En lo referente a las propuestas que se tenían para que el recién egresado pudiera encontrar empleo a la menor brevedad resaltó la importancia de crear la bolsa de trabajo, realizar prácticas profesionales en dependencias de gobierno y privadas, orientación sobre el campo laboral, reformar la enseñanza de varias materias (geografía económica, social, política y cultural), buscar la titulación por promedio, apresurar el trabajo de tesis, aprendizaje del idioma inglés, recorrer las dependencias donde puede trabajar el egresado, elaborar la tesis en el periodo señalado en la normatividad, salir del área de confort y buscar vacantes en otros estados, apoyarse en los profesores y sus contactos, prepararse en el campo que se quiere laborar, difusión de 
las áreas de la geografía en las empresas, oportunidades para desarrollar veranos de investigación y congresos, armar un buen $\mathrm{CV}$, mostrar dedicación y responsabilidad en el trabajo, encontrar motivación para titularse en menos tiempo, buscar experiencia en los veranos de investigación y modernizar los conocimientos en materias que son útiles en los empleos.

De igual modo, se sugirió hacer vinculaciones con instituciones y empresas privadas de diversos estados del país, crear una cuenta en la página del INEGI un año antes y estar revisando las convocatorias (debido que se emiten cada mes), realizar prácticas profesionales en el INEGI para mayor exposición, enviar solicitudes de empleo en diferentes empresas privadas y de gobierno antes de terminar la carrera, tomar cursos o conferencias acerca del tema de interés, vincularse con contactos conocidos que ya estén establecidos en empresas, expandir las prácticas profesionales y tesis a instituciones donde se oferten empleos de manera periódica, incrementar la experiencia en todas las áreas de la licenciatura, cumplimiento de un buen trabajo y aportar ideas, darse a conocer (en especial las nuevas generaciones), tomar los cursos que se imparten en las diferentes instalaciones de la universidad, titularse por medio de investigación (tesis), ya que es fundamental tener experiencia en dicho rubro, indagar opciones para elaborar la tesis en otras instituciones (como el Instituto de Geología, el Instituto de Geografía, el IMTA o el INEGI), o buscar contactos en las prácticas profesionales y servicio social. Por otra parte, se comentó cómo las dependencias se encuentran muy politizadas, puesto que entran personas involucradas en campañas de partidos políticos: "ya que todas las personas que contratan son su gente”.

Respecto a las entrevistas con informantes clave (expertos, especialistas y docentes), el sistema político prevaleciente al interior de la unidad local resultó lo más determinante, pues impacta de manera negativa en los proyectos y propuestas sobre mercado laboral, en la vinculación con dependencias, empresas y escuelas afines, en la difusión de nuevas vacantes y también en la aplicación académica del plan de estudios.

En este tenor, se enfatizó la falta de libertad para realizar investigación de al to nivel, el bloqueo de actividades docentes, así como el retraso en la acreditación y revisión del plan correspondiente. Además, se mencionó el despido de maestros de manera injustificada y la reubicación de educadores por intimidación, acoso y amenazas. Todo lo anterior fue conducido por grupos de poder locales y sus intereses particulares.

\section{Mercado laboral de los egresados de la Licenciatura en Geoinformática de la Universidad Autónoma de Ciudad Juárez, Chinuahua}

Para el caso de la Licenciatura en Geoinformática de la Universidad Autónoma de Ciudad Juárez, contestó la encuesta un total de 16 egresados (100\%). De ellos, $50 \%$ (8 casos) trabajaba en áreas afines a la geoinformática, $38 \%$ ( 6 casos) manifestó laborar en otros rubros diferentes, $6 \%$ ( 1 alumno) mencionó estar desempleado y otro $6 \%$ ( 1 caso) declaró dedicarse de tiempo completo a la tesis de maestría (gráfica 2 ).

De 50\% (8 casos) de egresados que se empleaban en áreas afines a la geoinformática, sus ingresos oscilaron desde $\$ 23000.00$ pesos mensuales como máximo hasta $\$ 9000.00$ mensuales como mínimo (tabla 2). Aquí resulta interesante resaltar que un egresado tuvo el salario más alto de todos los casos: el de $\$ 23000.00$ pesos mensuales, quien también superó al ingreso más alto de todo el grupo de geografía que laboraba en áreas afines a su profesión, ya que en éste último grupo el mayor salario fue de \$21 000.00 mensuales.

También destacó cómo tres de ellos declararon estar en el área de docencia en el nivel superior (de tiempo completo), pero con un salario relativamente bajo para tal nivel de responsabilidad, ya que osciló entre $\$ 9$ 657.00 y $\$ 9000.00$ pesos mensuales.

Las principales ciudades en donde se encontraban fueron Ciudad Cuauhtémoc y Ciudad Juárez (Chihuahua), Morelia (Michoacán) y Monterrey (Nuevo León). Resaltó aquí como todas las actividades a las que se dedican estaban relacionadas con las áreas de geoinformática. 
Asimismo, los puestos fueron variados, ya que van desde profesor de tiempo completo, funcionario, empleado de área, empleado por contrato de proyecto, hasta investigador.

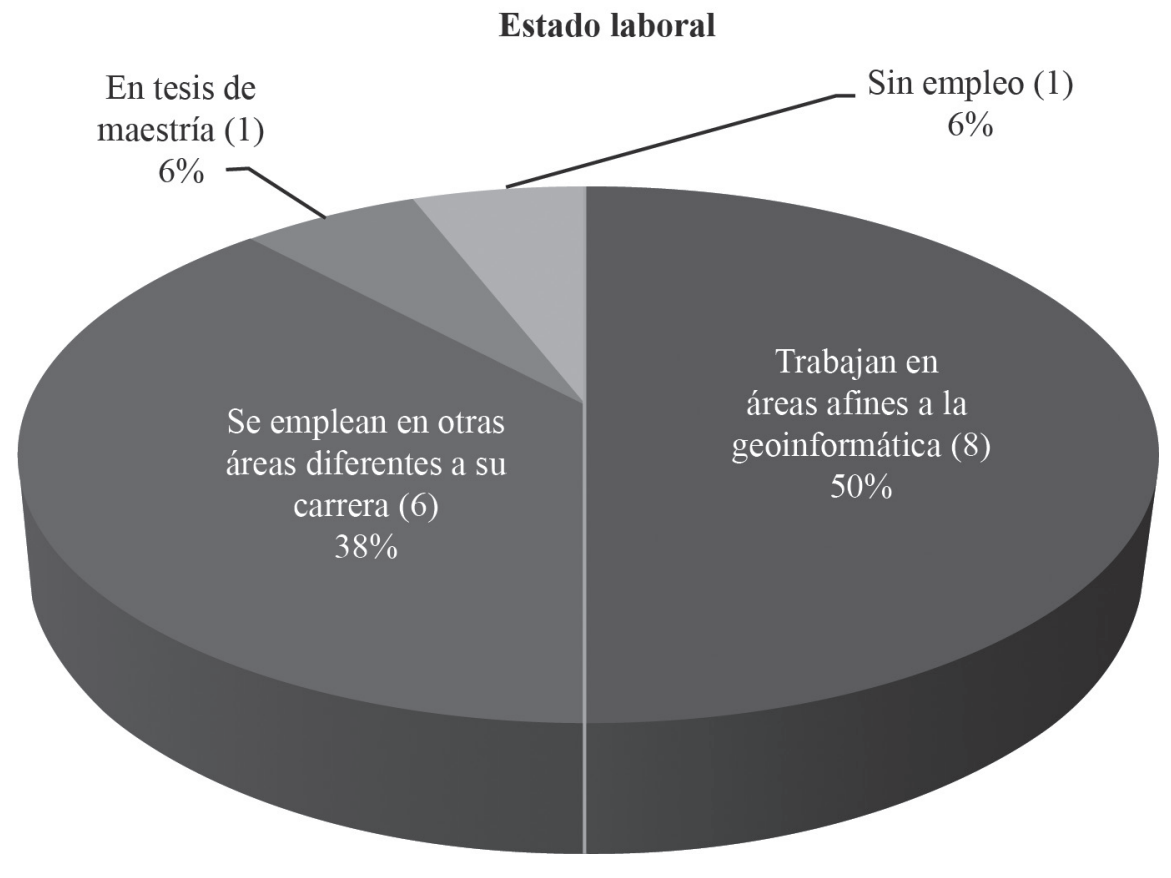

GRÁFICA 2

Total de egresados que trabajan en áreas afines a la geoinformática, en otras áreas y desempleados, 2017 Fuente: elaboración propia, 2018.

Nota: número total de egresados encuestados: 16 (100\%).

TABLA 2

Características laborales de egresados que trabajan en áreas afines a la geoinformática, 2017

\begin{tabular}{|c|c|c|c|c|}
\hline $\begin{array}{l}\text { Institución y/o } \\
\text { empresa* }\end{array}$ & $\begin{array}{c}\text { Ciudad y estado } \\
\text { donde se encuentran } \\
\text { laborando }\end{array}$ & Puesto & Actividad & $\begin{array}{c}\text { Salario mensual } \\
\text { (en pesos } \\
\text { mexicanos) }\end{array}$ \\
\hline $\begin{array}{l}\text { Observatorio } \\
\text { Ciudadano de } \\
\text { Prevención, } \\
\text { Seguridad y Justicia } \\
\text { del FICOSEC }\end{array}$ & $\begin{array}{l}\text { Ciudad Juárez, } \\
\text { Chihuahua }\end{array}$ & Investigación & $\begin{array}{l}\text { Investigación, georreferenciación, análisis } \\
\text { a delictivo }\end{array}$ & $\$ 23000.00$ \\
\hline $\begin{array}{l}\text { Institución de } \\
\text { gobierno }\end{array}$ & $\begin{array}{l}\text { Morelia, } \\
\text { Michoacán }\end{array}$ & Funcionario & $\begin{array}{l}\text { Análisis y modelado espacial } \\
\text { (aptitud urbana), vuelos con drones y } \\
\text { procesamiento de imágenes, análisis } \\
\text { estadístico (creación de instrumentos } \\
\text { metodológicos para la recolección de } \\
\text { datos y sistematización de información), } \\
\text { manejo de un sistema de información } \\
\text { geográfica y estadística en la web, } \\
\text { procesamiento y automatización de bases } \\
\text { de datos }\end{array}$ & $\$ 18900.00$ \\
\hline
\end{tabular}


TABLA 2 (continúa)

Características laborales de egresados que trabajan en áreas afines a la geoinformática, 2017

\begin{tabular}{|c|c|c|c|c|}
\hline $\begin{array}{l}\text { Institución y/o } \\
\text { empresa* }\end{array}$ & $\begin{array}{c}\text { Ciudad y estado } \\
\text { donde se encuentran } \\
\text { laborando }\end{array}$ & Puesto & Actividad & $\begin{array}{l}\text { Salario mensual } \\
\text { (en pesos } \\
\text { mexicanos) }\end{array}$ \\
\hline $\begin{array}{l}\text { Observatorio } \\
\text { Ciudadano de } \\
\text { FICOSEC }\end{array}$ & $\begin{array}{l}\text { Ciudad } \\
\text { Cuauhtémoc, } \\
\text { Chihuahua }\end{array}$ & $\begin{array}{l}\text { Empleado de } \\
\text { área }\end{array}$ & $\begin{array}{l}\text { Mapeo sociodemogáfico y delictivo } \\
\text { del municipio de Cuauhtémoc, así } \\
\text { como análisis diversos a partir de la } \\
\text { geoinformática que competen a la } \\
\text { empresa en materia de seguridad }\end{array}$ & $\$ 12000.00$ \\
\hline $\begin{array}{l}\text { Universidad } \\
\text { Autónoma de } \\
\text { Ciudad Juárez }\end{array}$ & $\begin{array}{l}\text { Ciudad Juárez, } \\
\text { Chihuahua }\end{array}$ & $\begin{array}{l}\text { Contrato por } \\
\text { proyecto }\end{array}$ & $\begin{array}{l}\text { Desarrollo de cartografía para proyecto } \\
\text { de evaluación del potencial territorial } \\
\text { para la densificación de usos de suelo } \\
\text { residencial en Ciudad Juárez, Chihuahua } \\
\text { Análisis de bases de datos en sistemas de } \\
\text { información geográfica } \\
\text { Recopilación y revisión de artículos para } \\
\text { desarrollar el proyecto relacionado con el } \\
\text { impacto que tienen los cambios de usos } \\
\text { de suelo en el cambio climático a partir } \\
\text { del análisis de imágenes satelitales con } \\
\text { sistemas de percepción remota } \\
\text { Colaboración con la creación de la } \\
\text { base de datos cartográfica de las rutas } \\
\text { de transporte público para } 28 \text { ciudades } \\
\text { mexicanas } \\
\text { Generación de indicadores de bienestar } \\
\text { social para estudiantes universitarios } \\
\text { Generación de cartografía de valor } \\
\text { catastral para Ciudad Juárez } \\
\text { Desarrollo de artículo de investigación } \\
\text { para la identificación de conflictos de } \\
\text { usos de suelo y para la planificación del } \\
\text { crecimiento urbano utilizando sistemas de } \\
\text { información geográfica }\end{array}$ & 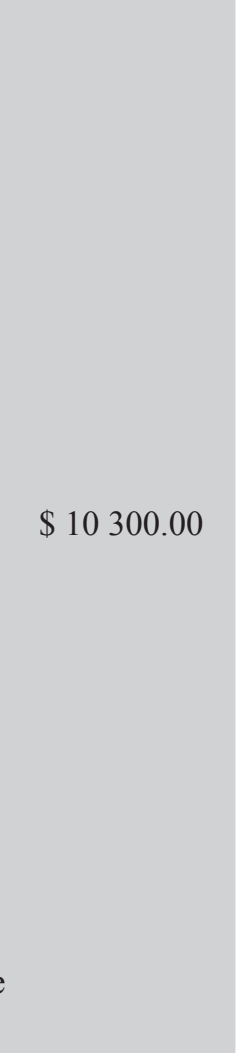 \\
\hline BIOALCEL & Monterrey & Empleado & $\begin{array}{l}\text { Mantener bases de datos actualizadas de } \\
\text { pacientes }\end{array}$ & $\$ 10000.00$ \\
\hline $\begin{array}{l}\text { Universidad } \\
\text { Autónoma de } \\
\text { Ciudad Juárez }\end{array}$ & $\begin{array}{l}\text { Ciudad } \\
\text { Cuauhtémoc, } \\
\text { Chihuahua }\end{array}$ & Profesor & Docencia y tutorías & $\$ 9657.00$ \\
\hline $\begin{array}{l}\text { Universidad } \\
\text { Autónoma de } \\
\text { Ciudad Juárez }\end{array}$ & $\begin{array}{l}\text { Ciudad } \\
\text { Cuauhtémoc, } \\
\text { Chihuahua }\end{array}$ & Profesor & $\begin{array}{l}\text { Docencia, tutoría, proyectos, } \\
\text { investigación, administración }\end{array}$ & $\$ 9000.00$ \\
\hline $\begin{array}{l}\text { Universidad } \\
\text { Autónoma de } \\
\text { Ciudad Juárez }\end{array}$ & $\begin{array}{l}\text { Ciudad } \\
\text { Cuauhtémoc, } \\
\text { Chihuahua }\end{array}$ & Profesor & Docencia & $\$ 9000.00$ \\
\hline
\end{tabular}

Fuente: elaboración propia, 2018. 
Por otra parte, de $8 \%$ (6 casos) que manifestó laborar en áreas diferentes a la geoinformática, los ingresos oscilaron desde $\$ 20000.00$ pesos mensuales como máximo hasta $\$ 3200.00$ pesos mensuales como mínimo (tabla 3). Y las ciudades donde se ubicaron fueron Anáhuac y Ciudad Cuauhtémoc (Chihuahua).

TABLA 3

Características laborales de egresados que trabajan en otras áreas diferentes a la geoinformática, 2017

\begin{tabular}{|c|c|c|c|c|}
\hline $\begin{array}{l}\text { Institución y/o } \\
\text { empresa* }\end{array}$ & Ciudad y estado & Puesto & Actividad & $\begin{array}{l}\text { Salario mensual (en } \\
\text { pesos mexicanos) }\end{array}$ \\
\hline Carpintería & Anáhuac, Chihuahua & Empleado & Carpintería & $\$ 20000.00$ \\
\hline $\begin{array}{l}\text { Cadena de } \\
\text { farmacias en } \\
\text { formación }\end{array}$ & $\begin{array}{l}\text { Ciudad Cuauhtémoc, } \\
\text { Chihuahua }\end{array}$ & Supervisor & $\begin{array}{l}\text { Se realiza un sistema informático } \\
\text { funcional para abastecer las } \\
\text { necesidades de una cadena de } \\
\text { farmacias en formación } \\
\text { Supervisión de la misma área y } \\
\text { del personal que labora en dichas } \\
\text { farmacias }\end{array}$ & $\$ 11200.00$ \\
\hline $\begin{array}{l}\text { Universidad } \\
\text { Autónoma de } \\
\text { Ciudad Juárez }\end{array}$ & $\begin{array}{l}\text { Ciudad Cuauhtémoc, } \\
\text { Chihuahua }\end{array}$ & Administración & $\begin{array}{l}\text { Servicios estudiantiles, atención } \\
\text { a estudiantes }\end{array}$ & $\$ 10000.00$ \\
\hline $\begin{array}{l}\text { Universidad } \\
\text { Autónoma de } \\
\text { Ciudad Juárez }\end{array}$ & $\begin{array}{l}\text { Ciudad Cuauhtémoc, } \\
\text { Chihuahua }\end{array}$ & Administración & $\begin{array}{l}\text { Administración de biblioteca, } \\
\text { préstamo de libros, } \\
\text { impresiones, copias, multas, } \\
\text { devolución de libros }\end{array}$ & $\$ 9000.00$ \\
\hline Taller de fundición & $\begin{array}{l}\text { Ciudad Cuauhtémoc, } \\
\text { Chihuahua }\end{array}$ & Empleado de área & Taller de fundición & $\$ 3200.00$ \\
\hline $\begin{array}{l}\text { Propietario de } \\
\text { taller }\end{array}$ & $\begin{array}{l}\text { Ciudad Cuauhtémoc, } \\
\text { Chihuahua }\end{array}$ & Propietario de taller & No especificado & Variable \\
\hline
\end{tabular}

Fuente: elaboración propia, 2018.

Respecto a las áreas donde los egresados consideran que deben reforzarse o incluirse en la carrera para que sea posible encontrar empleo con menor dificultad, se sugirió profundizar en la enseñanza relacionada con la programación para el desarrollo de software y herramientas SIG, practicar un enfoque más profundo de programación por medio de JAVA, reforzar los conceptos básicos de la geografía y otras ciencias que requieren del uso de SIG, mejorar el área de matemáticas (especialmente el análisis de series de tiempo), incluir web maping y desarrollo de aplicaciones móviles para la recolección de datos y geolocalización, adquirir experiencia en aplicaciones de drones y percepción remota con imágenes de alta resolución espacial (para el manejo de riesgos y procesos de planeación urbana), modernizar el manejo y automatización de bases de datos, implementar cursos para levantar datos en campo con drones, GPS y/o TTK, aumentar las prácticas de campo, incluir a los alumnos en los proyectos de investigación de docentes, así como crear una bolsa de trabajo específica para la licenciatura.

También se consideró que se debe tener una mayor participación en proyectos que permitan a los estudiantes mostrar sus habilidades y conocimientos en ramas afines a la geoinformática, difundir los trabajos realizados para buscar familiaridad entre instituciones y la labor que desarrollan los egresados, enfocarse en un tema y no extenderse mucho, aprendizaje del idioma inglés, incluir materias relacionadas con salidas de campo (y no enfocarse en el conocimiento técnico), reforzar la materia de ética profesional, evitar el descontrol al momento de asignar a docentes que no conocen bien de las materias en los primeros semestres, evitar que se enseñen los programas de computación hasta los últimos semestres, fomentar las prácticas profesionales, difundir la carrera (ya que es poco conocida), aplicar la geoinformatica a un trabajo en general, modernizar las áreas de programación y cartografía, enseñar programación en ambiente SIG desde inicios y durante toda la carrera (al ser uno de los campos donde 
existen más empleos) y que se impartan ocasionalmente clases técnicas en inglés (y no nada más acudir a las clases ofrecidas por el centro de lenguas).

Sobre las sugerencias para mejorar la carrera se consideró prioritario integrar a los alumnos en proyectos viables y de la vida real (así como estudiar la problemática actual de la ciudad), calificar los proyectos y brindar seguimiento y apoyo para que los alumnos se den a conocer (con el fin de que la población y empresas tengan un enfoque más claro sobre la importancia y el gran impacto que tiene la licenciatura), fomentar las potencialidades de la carrera en la región, centrar los temas que se imparten, reforzar el aprendizaje sobre el entorno geográfico y no solamente desde el punto de vista ambiental, analizar la totalidad de elementos que conforman el entorno y utilizar a la geoinformática como herramienta de estudio de un lugar, así como verificar el nombre de la carrera debido a que genera confusión con los empleadores (ya que piensan que es informática).

En esta misma vía, se sugirió preparar al alumno en diversos sectores especializados (hidrología, ciencias ambientales, manejo del territorio o aplicaciones en SIG) en lugar de llevar una tira de materias con conocimientos dispersos en varios campos, pero con poca preparación en cada una, fomentar prácticas profesionales a otros estados, buscar convenios de colaboración institucional para el desarrollo de tecnologías de la información geográfica y proyectos con impacto social, trabajar con temas sociales o políticos y no centrarse solamente en cuestiones ambientales y recursos naturales, enfocarse en cosas relacionadas a un trabajo y que las prácticas vayan más allá de cómo usar los programas, reforzar los ramos débiles que realmente se utilizarán en un empleo e impartir menos materias que no son muy importantes, disminuir las horas de teoría y apuntar a las cuestiones prácticas, vincularse con dependencias de gobierno para desarrollar proyectos y ayudar al estudiante a obtener una visión del mundo laboral o bien, incrementar el manejo de herramientas geotecnológicas.

En lo referente a las propuestas para que el recién egresado pueda encontrar empleo a la brevedad, sobresale la necesidad de vincularse con empresa particulares y de gobierno, la creación de una bolsa de trabajo regional, buscar el apoyo con docentes, quienes pueden conocer oportunidades laborales, revisar que las áreas de la carrera concuerden con las problemáticas regionales, salir de Ciudad Cuauhtémoc, dar de alta a la carrera en páginas de internet con bolsas de trabajo especiales para la profesión, verificar ofertas de trabajo en páginas de internet, participar en congresos con el fin de hacer contactos con investigadores, asistir a intercambios y veranos de investigación, incorporar a los alumnos a empresas e instituciones de gobierno con proyectos de desarrollo, además de vincular la licenciatura con los empleadores o dependencias potenciales.

Dentro del mismo rubro, resaltó la importancia de informar a los alumnos sobre las oportunidades laborales y académicas que tienen dentro y fuera del país, compartir experiencias entre egresados y colegas con los alumnos, obtener un mejor nivel del idioma inglés, desarrollar un buen CV sin faltas de ortografía, no tener miedo a decir "no sé, pero lo puedo intentar", vender mejor la carrera con el fin de dar a conocer ampliamente el trabajo que se puede generar, ofrecer prácticas en empresas que trabajen SIG para obtener experiencia, comenzar desde los primeros semestres de la carrera a desarrollar proyectos de investigación, publicar artículos y participar en congresos, buscar opciones laborales durante el último semestre y no al terminar los estudios (ya que el proceso puede tardar varios meses). También, se consideró que "es muy baja la oferta laboral y no es cuestión del egresado", así como "los estudios de licenciatura no son suficientes, por lo que es necesario optar por una maestría como opción para elevar el grado académico y las posibilidades de empleo".

En lo referente a la entrevistas con informantes clave (expertos, especialistas y docentes) destacó el constante enlace y vinculación que se realiza con dependencias, empresas y escuelas afines, el funcionamiento de la bolsa de trabajo para las profesiones que se imparten en dicha unidad multidisciplinaria, el amplio apoyo brindado hacia profesores-investigadores que realizan estancias de investigación relacionadas con proyectos sobre empleo, la implementación de estrategias para enfocar materias del plan de estudios a los problemas prioritarios regionales, y la permanente promoción de la carrera a nivel regional, estatal y nacional. Por último, se distinguió la amplia apertura que mostró el personal administrativo ante nuevas propuestas relacionadas con el mercado laboral. 
Entre las limitaciones mencionadas, se citó el bajo salario percibido por algunos profesores que laboraban de tiempo completo en dicha unidad, ya que percibían un promedio de $\$ 900.00$ pesos mensuales. Lo anterior debido a la alta responsabilidad que tienen dichos docentes para formar profesionistas con sólidas bases técnicas, teóricas y prácticas para que los estudiantes puedan satisfacer demandas de empleadores.

En las figuras 1 y 2 se observa la Unidad Multidisciplinaria de la Universidad Autónoma de Ciudad Juárez, ubicada en Ciudad Cuauhtémoc, Chihuahua. En la figura 3 se muestra la Unidad Académica de Ciencias de la Tierra de la Universidad Autónoma de Guerrero, en Taxco el Viejo, Guerrero.

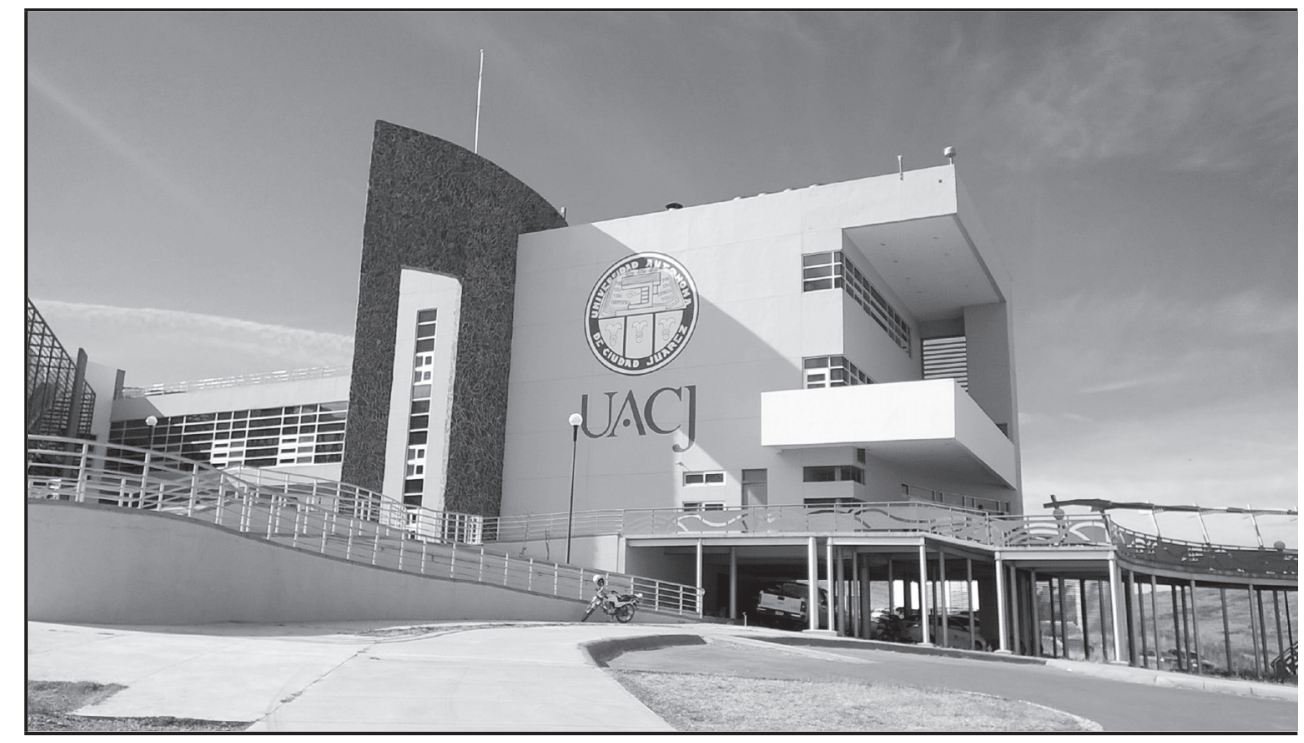

FIGURA 1

Unidad Multidisciplinaria de la Universidad Autónoma de Ciudad Juárez. Ciudad Cuauhtémoc, Chihuahua

Fuente: trabajo de campo, 2017.

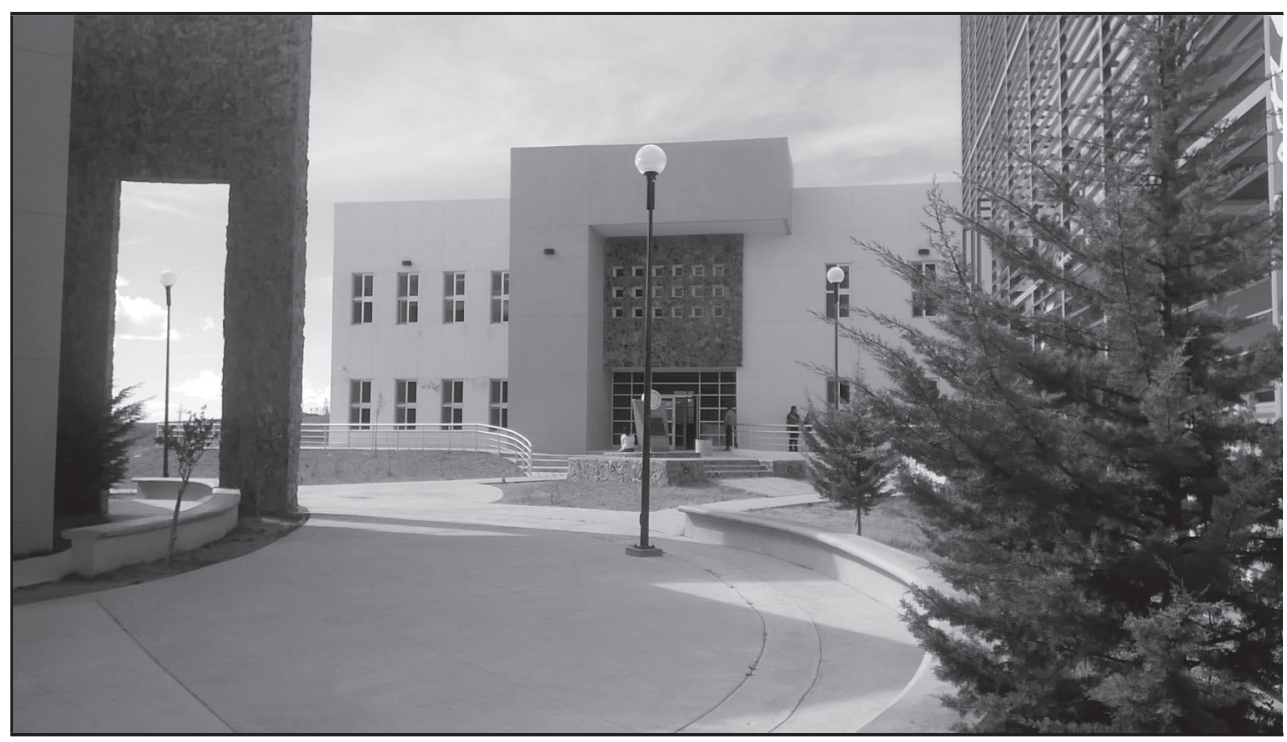

FIGURA 2

Unidad Multidisciplinaria de la Universidad Autónoma de Ciudad Juárez. Ciudad Cuauhtémoc, Chihuahua

Fuente: trabajo de campo, 2017. 


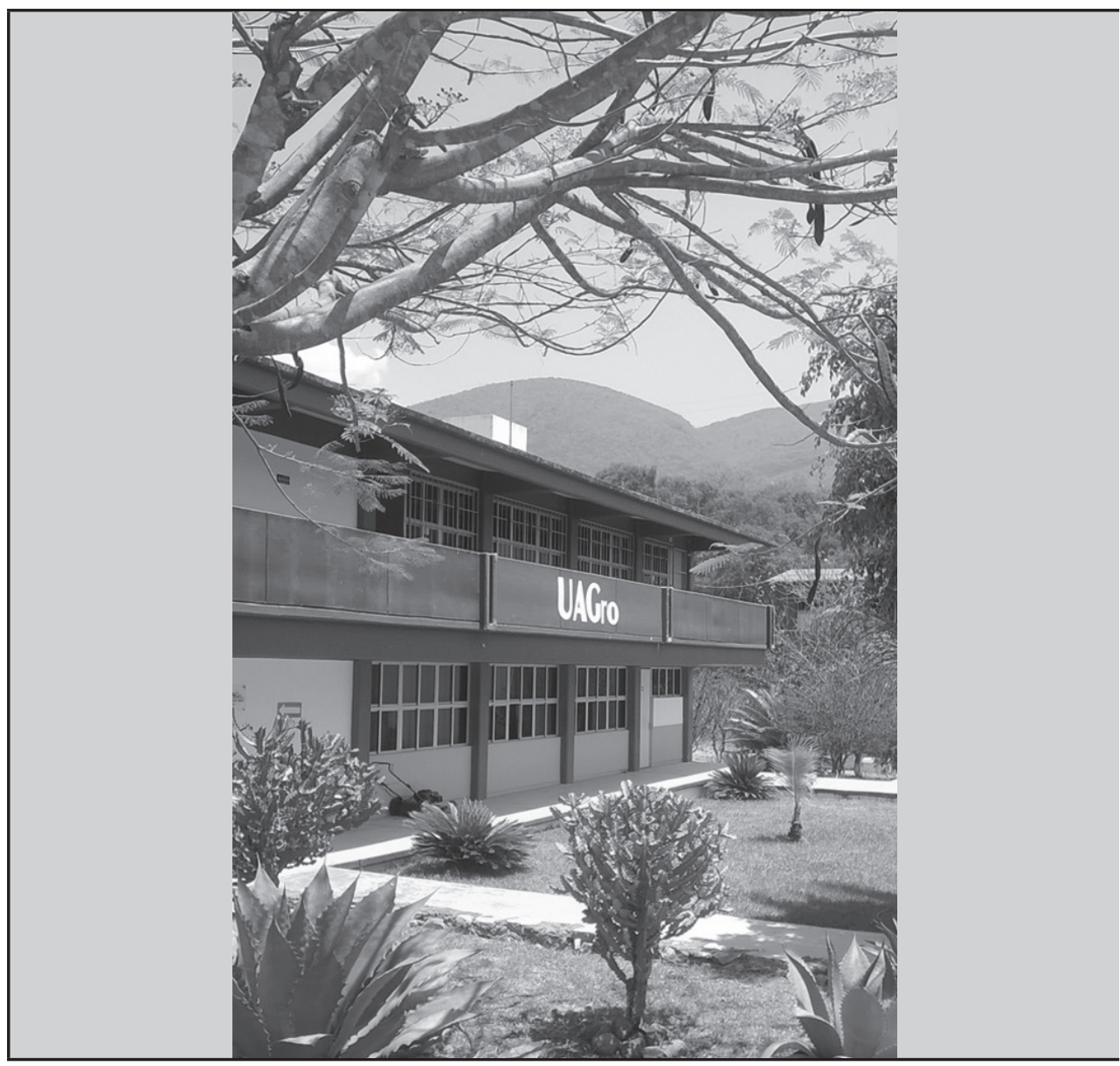

FIGURA 3

Unidad Académica de Ciencias de la Tierra de la Universidad Autónoma de Guerrero. Taxco el Viejo, Guerrero

Fuente: trabajo de campo, 2018.

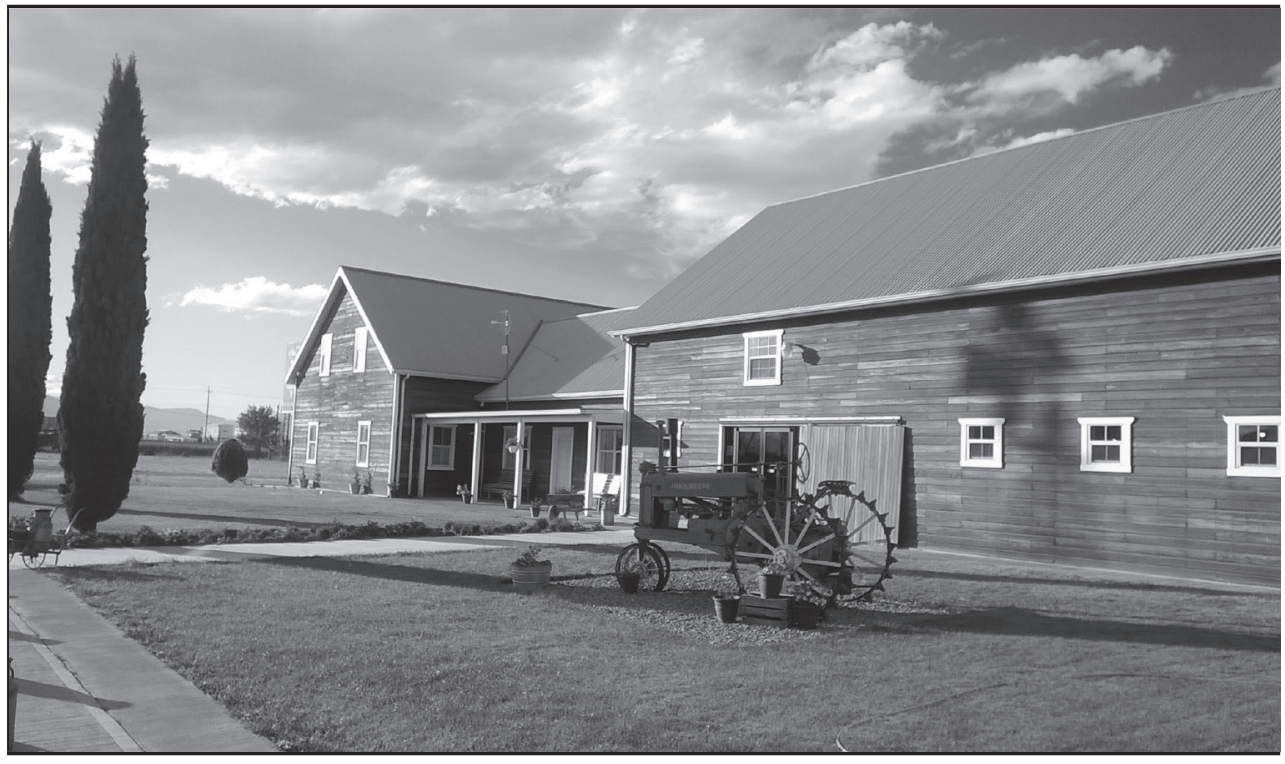

FIGURA 4

Museo Menonita. Ciudad Cuauhtémoc, Chihuahua

Fuente: trabajo de campo, 2017 


\section{Discusión}

Como se confirmó, autores como Escamilla et al. (2015) mencionan que no se alcanzan a cubrir los puestos de trabajo para las nuevas generaciones, así como la presencia de desempleo de profesionistas en la Región Centro de México. En este artículo también se confirmó que casi la tercera parte de los egresados de geografía encuestados (26\%) se encontraba en situación de desempleo.

En el mismo sentido, en las obras de Checa (2014) se especifica cómo el promedio de salarios mensuales brutos de los geógrafos para 2014 estaba entre $\$ 8785.00$ y $\$ 10571.00$ pesos. A diferencia de lo anterior, este trabajo realizado en 2017, los ingresos mensuales promedio de los egresados que laboraban en áreas afines a la geografía oscilaron entre $\$ 2000.00$ y $\$ 21000.00$ pesos.

Entre la gran diversidad de problemáticas observadas por Urióstegui (2011) en la Licenciatura en Geografía de la Universidad Autónoma del Estado de México destacó la lucha de grupos internos por el control político y de cargos. De manera similar, en la carrera impartida en la Unidad Académica de Ciencias de la Tierra también resaltaron los conflictos y las contiendas para obtener el poder entre agrupaciones al interior de dicha escuela. Al parecer, la esfera política fue determinante e impactó de manera adversa las cuestiones de docencia, investigación y en los estudios de mercado en estas dos últimas carreras citadas.

En otras obras de Checa (2013) se menciona la tendencia muy marcada sobre la presencia de egresados de geografía en el ámbito docente. A diferencia de esto, la ocupación en pedagogía de las personas encuestadas de geografía fue mínima ( 3 casos). Algunos obstáculos que tuvieron estos últimos fueron el tipo y cantidad de requisitos solicitados, exámenes, formas de elegir las vacantes, y los procesos administrativos solicitados por la Secretaría de Educación Pública y escuelas privadas, sobre todo para ingresar de tiempo completo al nivel medio y medio superior, tanto en el ámbito local como en la misma Región Norte del Estado de Guerrero.

También resultó fundamental rescatar la obra publicada en los noventa por parte de Chías et al. (1994) para resaltar la grave situación del mercado laboral de los egresados de geografía, suscitada en los setenta y ochenta. En los escritos de Burgos y López (2010) se menciona cómo una proporción importante de profesionistas no aplicaba plenamente los conocimientos y habilidades adquiridos en la universidad, entre muchas otras problemáticas. A diferencia de lo referido, la mayoría de los profesionistas encuestados de geografía y geoinformática que se encontraban laborando en áreas afines a su carrera manifestó que aplicaban en mayor o menor medida los conocimientos obtenidos en las aulas.

Es importante destacar cómo Urióstegui (2011) confirma la saturación de vacantes, y un grave desempleo y subempleo en la ciudad y Valle de Toluca para los profesionistas en geografía, debido sobre todo, al exceso de la matrícula de egresados de la Licenciatura en Geografía de la Universidad Autónoma del Estado de México. En el caso de la carrera de geografía ofertada en el Estado de Guerrero también es una preocupación latente, ya que $26 \%$ es el registro del porcentaje de desempleo.

A lo precedente, se le puede agregar que $14 \%$ se encontraba laborando en otras áreas diferentes a la profesión; por lo tanto, al sumar los dos porcentajes, se refleja $40 \%$ de alumnos desempleados y/o trabajando en rubros diferentes. Al panorama previo también se suma la alta competencia que tendrán las nuevas generaciones que están por salir de las aulas, y en específico para acceder a las vacantes regionales disponibles.

En el caso de geoinformática (y de los pocos trabajos accesibles) vale la pena destacar cómo la Universidad Autónoma de Ciudad Juárez (Universidad Autónoma de Ciudad Juárez-Dirección General de Planeación y Desarrollo Institucional, 2017) ha publicado compilaciones de estudios sobre seguimiento de egresados para el periodo 2007-2016. Aquí resalta en especial el punto de "trayectoria laboral", en donde se muestran los datos sobre el empleo de los egresados y que tanto éste se relaciona con sus estudios, así también el punto de "valoración", el cual refleja la opinión de los egresados hacia los servicios que la Universidad Autónoma de Ciudad Juárez proporciona, y qué tan satisfechos se encuentran con ellos. 
Cabe señalar que los resultados de este artículo pueden retroalimentar y enriquecer dichas propuestas sobre seguimiento de egresados, sobre todo con los datos explicados con mayor detalle en el anexo A y las tablas 1,2 y 3.

Otro escrito importante es el estudio de empleadores (Universidad Autónoma de Ciudad Juárez-Dirección General de Planeación y Desarrollo Institucional, 2016) que se llevó acabo en seis Institutos de la Universidad Autónoma de Ciudad Juárez, el cual incluyó a la licenciatura en geoinformática. Sin embargo, el inconveniente que presenta es que lo datos no se desglosan por licenciaturas, sino de manera global por institutos. Por lo tanto, esta investigación también puede potenciar los futuros análisis sobre empleadores para dicha profesión.

Vale la pena destacar cómo Magaña (2007) llega a explicar la perspectiva histórica del mercado de trabajo en México, así como varias propuestas metodológicas. Al respecto, el presente artículo puede reforzar los estudios de caso, y contribuir con datos recientes sobre empleo para las dos licenciaturas referidas.

Por otra parte, al analizar el plan de estudios de la Licenciatura en Geografía de la Universidad Autónoma de Guerrero (Universidad Autónoma de Guerrero, 2007) destacan varias áreas terminales avanzadas: a) ordenamiento territorial, b) geografía de los riesgos y de la vulnerabilidad, $c$ ) manejo y conservación de recursos naturales y d) geografía del desarrollo. También incluye las especialidades de cartografía, sistemas de información geográfica, teledetección y percepción remota, las cuales se implementan desde la etapa o núcleo de formación profesional específica.

Dicho plan fue elaborado en 2007 tomando en cuenta a) el análisis profundo de programas afines que se imparten en universidades de Estados Unidos, Canadá, Brasil, España y México, $b$ ) los datos de encuestas aplicadas a posibles empleadores (instituciones de educación, gubernamentales, de investigación y del sector social) yc) al registrar las problemáticas locales y regionales prioritarias y específicas del estado de Guerrero tales como pobreza extrema, marginación, bajo nivel educativo, desempleo, migración, crecimiento desordenado de ciudad, y la explotación desmedida y destrucción de recursos naturales.

Asimismo, se incluyó el estudio del impacto negativo de fenómenos naturales, biológicos y humanos, e inclusive, temas de vulnerabilidad, riesgos y catástrofes (sismos, huracanes, deslizamientos, inundaciones, incendios, contaminación por desechos químicos e industriales, o por la transmisión de enfermedades epidémicas y pandémicas), por citar algunos datos.

Del mismo modo, y como breve ejemplo, la asignatura de geografía del desarrollo fue orientada a elaborar, implementar, monitorear y evaluar programas de desarrollo en diversos sectores, así como para proponer alternativas para la reactivación de actividades económicas locales y regionales. Lo anterior desde el punto de vista geográfico, sin olvidar los métodos de medición de la pobreza, y el estudio de la distribución territorial de la pobreza extrema por entidad federativa, y en los municipios de México.

Ahora bien, al confrontar los postulados teóricos del plan de estudios de la licenciatura en geografía ante las áreas donde trabajaban los egresados encuestados y las actividades especializadas que realizaban (y que de acuerdo con sus declaraciones llevaban a cabo en su empleo formal), se confirmó cómo las disciplinas que más se solicitaron en dependencias gubernamentales, privadas y/o de docencia fueron los sistemas de información geográfica, la cartografía, la geografía del desarrollo con su respectivo trabajo de campo (enfocado a la difusión, implementación y monitoreo de programas gubernamentales de desarrollo en comunidades urbanas, rurales, étnicas y marginadas) y la pedagogía (en el nivel medio, medio superior y superior).

Otras materias donde también se encontraban laborando los egresados (directa o indirectamente) fueron geografía económica, geografía rural, geografía agraria, geografía de la población, geografía urbana, geografía cultural, geografía física, estadística, hidrología, geología aplicada a la minería y percepción remota.

No se registraron egresados laborando en los campos de ordenamiento territorial ni tampoco en geografía de los riesgos (disciplinas avanzadas contempladas en el plan correspondiente).

Tomando en cuenta lo anterior, los administrativos de dicho programa podrían analizar esta información y determinar si es posible reforzar las líneas, especialidades y asignaturas que tienen mayor demanda económica y práctica con el fin de que el egresado posea mejores alternativas o pueda ser considerado para nuevas vacantes y logre adecuarse y/o adaptarse en la medida de lo posible, a los requerimientos de los empleadores. 


\section{Conclusiones}

La propuesta teórico-metodológica de "estudios de opiniones de egresados y empleadores" (Gómez citado por Magaña, 2007) sirvió de guía para estudiar el mercado laboral de las licenciaturas en cuestión (principal objetivo de la obra). Se considera que algunos de los resultados de la presente obra pueden ser útiles para indagar futuras opciones a la empleabilidad. Como se observó, los análisis sobre las determinantes de la empleabilidad de los jóvenes universitarios y sus alternativas para promoverla pueden consultarse con mayor profundidad en las obras de Muñoz (2006).

Como referencia para profesores, investigadores, egresados y alumnos interesados en la temática se confirmó que los salarios para la carrera de geografía oscilaron entre un máximo de $\$ 21000.00$ mensuales y un mínimo de $\$ 2400.00$ pesos mensuales. En geoinformática los salarios fueron desde $\$ 23000.00$ pesos mensuales como máximo hasta $\$ 900.00$ mensuales como mínimo.

Para las dos licenciaturas resaltó un amplio panorama de propuestas y sugerencias de parte de los egresados, las cuales pueden ser consideradas para mejorar los planes de estudio correspondientes. En este sentido, también se registraron interesantes ideas y recomendaciones para que los alumnos que están por egresar logren encontrar un cargo a la brevedad tomando en cuenta las experiencias de los profesionistas encuestados.

Esta información también orienta a los estudiantes que cursan los primeros años y se encuentran interesados en la búsqueda de vacantes acordes con su vocación personal. Asimismo, pueden vislumbrarse los tipos de actividades realizadas y salarios percibidos.

Como se registró (comunicación personal con informantes anónimos, 2018), al iniciar la carrera de geografía había un equipo que investigaba, monitoreaba y difundía convocatorias y vacantes laborales en dicho sector. Cuando este mecanismo se encontraba vigente, tanto egresados como alumnos de todos los semestres podían tener acceso al panorama referente a su campo de ocupación, salarios y prestaciones ofrecidas, así como también enterarse de la diversidad de dependencias, empresas y escuelas en donde podían adquirir las primeras experiencias profesionales.

Asimismo, las sugerencias que mencionaron los egresados encuestados y especialistas entrevistados sobre cómo mejorar las carreras en cuestión y su mercado laboral específico también pueden enriquecer la futura elaboración de los programas y planes de estudio correspondientes, sin descuidar en éstos últimos el panorama sobre las actuales demandas que solicitan empresas y dependencias afines.

Desde el punto de vista de las ciencias políticas, vale la pena ratificar que es extremadamente difícil desarrollar, difundir y lograr altos estándares en cuestiones de docencia e investigación cuando existe un ambiente de trabajo donde la prioridad es la lucha por acceder a los puestos administrativos, y cuando las cuestiones relacionadas con el rubro de mercado laboral, deserción escolar, escasa titulación, baja matrícula de alumnos y nula producción de publicaciones, pasan a último término o, en su caso, no tienen ninguna importancia para los grupos que buscan obtener o preservar el poder local.

Por otra parte, y por el grado de complejidad, se deja para estudios posteriores el análisis sobre cuestiones de hegemonía, control, poder, estrategias utilizadas, mecanismos de represión, intimidación y acoso, y conductas serviles que se suscitan en dichos espacios locales.

\section{Análisis prospectivo}

Los resultados presentados quizá puedan servir a los administrativos, docentes e investigadores para optimizar, enriquecer o mejorar la vinculación entre los empleadores y las escuelas referidas, así como también, para actualizar y ampliar el conocimiento sobre las características de áreas y especialidades más redituables en el aspecto económico para los egresados y de sus diversas vacantes disponibles.

Asimismo, sería interesante confrontar el panorama de lo aquí expuesto ante nuevos proyectos y obras 
relacionadas con el empleo y bolsa de trabajo de las profesiones en cuestión.

Finalmente, se invita a continuar con los estudios de mercado laboral en las disciplinas de geografía y geoinformática, con el fin de colaborar en el desarrollo de estas especializadas ramas científicas, conocer el rango de salarios y sectores de mayor demanda, y fomentar con esta información, un mayor reconocimiento para dichas licenciaturas en México.

\section{Agradecimientos}

Se agradecen los comentarios de los árbitros de la revista que mejoraron sustancialmente el contenido del artículo.

\section{REFERENCIAS}

Amaro, J. A., Anaya, M., Corona, J. P., Lozano, K. M., Márquez B. y Morales, F. (2010). Análisis del mercado laboral del geógrafo: opinión de los empleadores de los egresados de la licenciatura en geografía. Subcomisión de Empleadores. Comisión de Evaluación del Plan de Estudios de la Licenciatura en Geografía. Diagnóstico del Programa de la Licenciatura en Geografía. Periodo 2004-2009. México: Universidad de Guadalajara.

Amezcua, J. J., Robles, J. D., Rodríguez, J. y Rodríguez, R. (2010). Diagnóstico de egresados de la Licenciatura en Geografía. Subcomisión de egresados. Comisión de Evaluación del Plan de Estudios de la Licenciatura en Geografía. Diagnóstico del Programa de la Licenciatura en Geografía. Periodo 2004-2009. México: Universidad de Guadalajara.

Burgos, B. y López, C. (2010). La situación del mercado laboral de profesionistas. Revista de la Educación Superior, 39(156), 19-33. México: Asociación Nacional de Universidades e Instituciones de Educación Superior.

Castañeda, J. (2006). La enseñanza de la geografía en México: una visión histórica, 1821-2005. México: Plaza y Valdés.

Checa, M. M. (2014). El egresado en geografía en México, sus competencias profesionales en el mercado laboral. Biblio 3W. Revista Bibliográfica de Geografía y Ciencias Sociales, 19(1060) España: Universidad de Barcelona. Disponible en http://www.ub.edu/geocrit/b3w-1060.htm

Checa, M. M. (2013). Competencias profesionales del licenciado en geografía en México. México: División de Ciencias Sociales y Humanidades-UAM I. Disponible en http://csh.izt.uam.mx/sistemadivisional/SDIP/ proyectos/archivos_rpi/dea_35150_66_479_9_1_1_Informe_Competencias.pdf

Chías, L., Cruz, J. y Malcon, A. (1994). Desarrollo de la geografía universitaria: el Colegio de Geografía-UNAM y sus planes de estudio, en Guillermo Aguilar Adrián y Omar Moncada (Comps.), La geografía humana en México (pp. 76-91). México: Universidad Nacional Autónoma de México, Fondo de Cultura Económica.

Escamilla, I., Santos, C. y Rezago, B. D. (2015). Mercado laboral en la Región Centro de México: ¿Avances o retrocesos en la población trabajadora en los últimos años? XX Encuentro Nacional sobre Desarrollo Regional en México. México: AMECIDER-CRIM, UNAM.

Escamilla, I. y Santos, C. (s/f). El mercado laboral en México desde la perspectiva de geografía del género. México: Instituto de Geografía, Universidad Nacional Autónoma de México. Disponible en http:// observatoriogeograficoamericalatina.org.mx/egal9/Geografiasocioeconomica/Geografiacultural/05.pdf

Franco, R. (2008). Plan de desarrollo 2008-2012. Facultad de Geografía. Toluca: Universidad Autónoma del Estado de México.

Hernández, R., Fernández, C. y Pilar, B. (2010). Metodología de la investigación. México: McGraw-Hill.

Magaña, H. (2007). Metodologías para el estudio de los mercados laborales. Remo. Revista mexicana de orientación educativa, 5(12), 1-8. México: Centro de Investigación y Formación para la Docencia y Orientación Educativa, S. C.

Muñoz, C. (2006). Determinantes de la empleabilidad de los jóvenes universitarios y alternativas para promoverla. 
Papeles de población, 49, 75-89. México: Universidad Autónoma del Estado de México.

Universidad Autónoma de Ciudad Juárez-Dirección General de Planeación y Desarrollo Institucional. (2017). Estudio de seguimiento de egresados a 2 años. DMC. Licenciatura en geoinformática. México: Universidad Autónoma de Ciudad Juárez-Dirección General de Planeación y Desarrollo Institucional.

Universidad Autónoma de Ciudad Juárez-Dirección General de Planeación y Desarrollo Institucional. (2016). Estudio de empleadores. México: Universidad Autónoma de Ciudad Juárez-Dirección General de Planeación y Desarrollo Institucional.

Universidad Autónoma de Ciudad Juárez. (2017). Matrículas de alumnos del Campus Ciudad Cuaubtémoc, Chihuahua. México: Universidad Autónoma de Ciudad Juárez.

Universidad Autónoma de Guerrero (2018). Lista de alumnos por periodo lectivo, grado, grupo y turno. Periodo lectivo: febrero 2018-julio 2018. México: Universidad Autónoma de Guerrero-Unidad Académica de Ciencias de la Tierra.

Universidad Autónoma de Guerrero. (2007). Nuevo Plan Educativo. Licenciatura en Geografía. México: Universidad Autónoma de Guerrero.

Urióstegui, A. (1995). Seguimiento de egresados para la licenciatura en geografía. Generación 1992, en la ciudad de Toluca. Papeles de Población, 6(7), 85-98. México: Universidad Autónoma del Estado de México.

Urióstegui, A. (1996). Educación y mercado laboral: un acercamiento hacia las zonas de primer empleo y técnicas profesionales de la licenciatura en geografía de la UAEM en la ciudad de Toluca. Educativa, 4(7), 31-41. México: Secretaría de Educación, Cultura y Bienestar Social-Gobierno del Estado de México.

Urióstegui, A. (2011). Egresados de la Licenciatura en Geografía de la Universidad Autónoma de Guerrero. Tlamati (sabiduria), 3(1), 56-64.

ANEXO A

Características laborales de egresados que trabajan en áreas afines a la geografía, 2017

\begin{tabular}{|c|c|c|c|c|}
\hline Institución y/o empresa & Ciudad y estado & Puesto & Actividades & $\begin{array}{l}\text { Salario mensual } \\
\text { (en pesos } \\
\text { mexicanos) }\end{array}$ \\
\hline Escuela privada & Querétaro, Querétaro & Profesor & Docencia & $\$ 21000.00$ \\
\hline Industria Peñoles & Fresnillo, Zacatecas & Empleado & Actividades de minería & $\$ 15000.00$ \\
\hline $\begin{array}{l}\text { Secretaría de Desarrollo } \\
\text { Social (SEDESOL) }\end{array}$ & Taxco, Guerrero & Supervisor & $\begin{array}{l}\text { Supervisión en comedores } \\
\text { comunitarios }\end{array}$ & $\$ 13000.00$ \\
\hline $\begin{array}{l}\text { Instituto Mexicano de } \\
\text { Tecnología del Agua } \\
\text { (IMTA) }\end{array}$ & Cuernavaca, Morelos & $\begin{array}{l}\text { Profesionista } \\
\text { especializado }\end{array}$ & $\begin{array}{l}\text { Cartografía, revisión de } \\
\text { información geográfica, estudios } \\
\text { espaciales y apoyo en campo }\end{array}$ & $\$ 12000.00$ \\
\hline $\begin{array}{l}\text { Banco privado } \\
\text { (servicios financieros) }\end{array}$ & Ciudad de México & $\begin{array}{l}\text { Analista de } \\
\text { geomarketing }\end{array}$ & $\begin{array}{l}\text { Estudios de mercado, cartografía } \\
\text { en sistemas de información } \\
\text { geográfica }\end{array}$ & $\$ 11000.00$ \\
\hline Empresa privada & Ciudad de México & Asesor & $\begin{array}{l}\text { Elaboración cartográfica } \\
\text { en sistemas de información } \\
\text { geográfica }\end{array}$ & $\$ 10000.00$ \\
\hline $\begin{array}{l}\text { Instituto Mexicano de } \\
\text { Tecnología del Agua } \\
\text { (IMTA) }\end{array}$ & Cuernavaca, Morelos & $\begin{array}{l}\text { Profesionista } \\
\text { especializado }\end{array}$ & $\begin{array}{l}\text { Revisión de información } \\
\text { proporcionada por empresas } \\
\text { contratadas por el IMTA } \\
\text { (datos estadísticos, plataforma } \\
\text { geográfica), realización de } \\
\text { cartografía y análisis espacial de } \\
\text { los datos }\end{array}$ & $\$ 8500.00$ \\
\hline
\end{tabular}


ANEXO A (continúa)

Características laborales de egresados que trabajan en áreas afines a la geografía, 2017

\begin{tabular}{|c|c|c|c|c|}
\hline Institución y/o empresa & Ciudad y estado & Puesto & Actividades & $\begin{array}{l}\text { Salario mensual } \\
\text { (en pesos } \\
\text { mexicanos) }\end{array}$ \\
\hline Empresa privada & Cuernavaca, Morelos & Empleado & $\begin{array}{l}\text { Elaboración cartográfica } \\
\text { en sistemas de información } \\
\text { geográfica, datos censales }\end{array}$ & $\$ 8000.00$ \\
\hline $\begin{array}{l}\text { Instituto Nacional de } \\
\text { Estadística, Geografía } \\
\text { e Informática }\end{array}$ & Cuernavaca, Morelos & Funcionario & $\begin{array}{l}\text { Actualización e integración de } \\
\text { domicilios }\end{array}$ & $\$ 8000.00$ \\
\hline $\begin{array}{l}\text { Instituto Nacional de } \\
\text { Estadística, Geografía } \\
\text { e Informática }\end{array}$ & Cuernavaca, Morelos & Empleado & $\begin{array}{l}\text { Elaboración de cartografía, } \\
\text { aplicación de sistemas de } \\
\text { información geográfica para } \\
\text { análisis de la distribución del } \\
\text { uso de suelo en zonas rurales } \\
\text { y urbanas y su posterior } \\
\text { modificación comparando años } \\
\text { anteriores }\end{array}$ & $\$ 8000.00$ \\
\hline $\begin{array}{l}\text { Universidad Autónoma } \\
\text { de Morelos }\end{array}$ & Cuernavaca, Morelos & Técnico & $\begin{array}{l}\text { Elaboración de cartografía } \\
\text { mediante sistemas de } \\
\text { información geográfica }\end{array}$ & $\$ 7000.00$ \\
\hline $\begin{array}{l}\text { Ayuntamiento de } \\
\text { Taxco de Alarcón }\end{array}$ & Taxco, Guerrero & Empleado & Docencia & $\$ 6500.00$ \\
\hline $\begin{array}{l}\text { Secretaría de } \\
\text { Desarrollo Social } \\
\text { (SEDESOL) }\end{array}$ & Guadalajara, Jalisco & Empleado & $\begin{array}{l}\text { Captura de información, } \\
\text { aplicación de encuestas, pago de } \\
\text { cheques del Programa } 70 \text { y más }\end{array}$ & $\$ 6000.00$ \\
\hline $\begin{array}{l}\text { Secretaría de } \\
\text { Desarrollo Social } \\
\text { (SEDESOL) }\end{array}$ & Guadalajara, Jalisco & Empleado & $\begin{array}{l}\text { Captura de información, } \\
\text { aplicación de encuestas, pago de } \\
\text { cheques del Programa } 70 \text { y más }\end{array}$ & $\$ 6000.00$ \\
\hline $\begin{array}{l}\text { Secretaría de } \\
\text { Desarrollo Social } \\
\text { (SEDESOL) }\end{array}$ & Guadalajara, Jalisco & Empleado & $\begin{array}{l}\text { Captura de información, } \\
\text { aplicación de encuestas, pago de } \\
\text { cheques del Programa } 70 \text { y más }\end{array}$ & $\$ 6000.00$ \\
\hline $\begin{array}{l}\text { Secretaría de } \\
\text { Desarrollo Social } \\
\text { (SEDESOL) }\end{array}$ & Guadalajara, Jalisco & Empleado & $\begin{array}{l}\text { Captura de información, } \\
\text { aplicación de encuestas, pago de } \\
\text { cheques del Programa } 70 \text { y más }\end{array}$ & $\$ 6000.00$ \\
\hline $\begin{array}{l}\text { Secretaría de Desarrollo } \\
\text { Social (SEDESOL) }\end{array}$ & Taxco, Guerrero & Supervisor & $\begin{array}{l}\text { Reconocimiento de localidades, } \\
\text { trabajo de campo y de gabinete, } \\
\text { elaboración de diagnósticos sobre } \\
\text { aspectos económicos, sociales y } \\
\text { físicos }\end{array}$ & $\$ 5900.00$ \\
\hline $\begin{array}{l}\text { Secretaría de Desarrollo } \\
\text { Social (SEDESOL) }\end{array}$ & Taxco, Guerrero & Empleado & Encuestas en comunidades & $\$ 5900.00$ \\
\hline CIPRO & Iguala, Guerrero & Profesor & Docencia & $\$ 2400.00$ \\
\hline $\begin{array}{l}\text { Secretaría de } \\
\text { Medio Ambiente y } \\
\text { Recursos Naturales } \\
\text { (SEMARNAT) }\end{array}$ & $\begin{array}{l}\text { Chilpancingo, } \\
\text { Guerrero }\end{array}$ & Asesor & $\begin{array}{l}\text { Asesoría sobre proyectos } \\
\text { agropecuarios }\end{array}$ & $\begin{array}{l}\text { La institución } \\
\text { paga } \$ 2500.00 \\
\text { por cada } \\
\text { productor y/o } \\
\text { campesino que } \\
\text { recibe asesoría }\end{array}$ \\
\hline $\begin{array}{l}\text { Secretaría de Desarrollo } \\
\text { Rural }\end{array}$ & Taxco, Guerrero & Asesor & $\begin{array}{l}\text { Asesoría sobre } \\
\text { georreferenciación cartográfica }\end{array}$ & $\begin{array}{l}\$ 600.00 \text { por } \\
\text { cada asesoría }\end{array}$ \\
\hline
\end{tabular}


ANEXO A (continúa)

Características laborales de egresados que trabajan en áreas afines a la geografía, 2017

\begin{tabular}{|c|c|c|c|c|}
\hline Institución y/o empresa & Ciudad y estado & Puesto & Actividades & $\begin{array}{l}\text { Salario mensual } \\
\text { (en pesos } \\
\text { mexicanos) }\end{array}$ \\
\hline $\begin{array}{l}\text { Instituto Mexicano de } \\
\text { Tecnología del Agua } \\
\text { (IMTA) }\end{array}$ & Cuernavaca, Morelos & $\begin{array}{l}\text { Profesionista } \\
\text { especializado }\end{array}$ & $\begin{array}{l}\text { Verificación y validación de } \\
\text { bases de datos y plataforma } \\
\text { geográfica por medio de } \\
\text { ArcGIS de proyecto de pozos de } \\
\text { aprovechamiento, descargas, y } \\
\text { zonas federales }\end{array}$ & $\begin{array}{l}\text { De } \$ 9000.00 \\
\text { a } \$ 11000.00 \\
\text { pesos (variable) }\end{array}$ \\
\hline Ayuntamiento de Taxco & Taxco, Guerrero & Técnico & Información geográfica & $\begin{array}{l}\text { De } \$ 2000.00 \\
\text { a } \$ 4000.00 \\
\text { (variable) }\end{array}$ \\
\hline Empresa privada & Ciudad de México & Empleado & $\begin{array}{l}\text { Cartografía y sistemas de } \\
\text { información geográfica }\end{array}$ & No contestó \\
\hline $\begin{array}{l}\text { INyDES (empresa } \\
\text { privada del sector } \\
\text { forestal) }\end{array}$ & Ciudad de México & Empleado & $\begin{array}{l}\text { Cartografía, análisis de datos, } \\
\text { bases de datos }\end{array}$ & No contestó \\
\hline $\begin{array}{l}\text { Guayana Mining } \\
\text { Construction S. A. de } \\
\text { C. V. }\end{array}$ & Ciudad de México & Supervisor & $\begin{array}{l}\text { Supervisión a empresa encargada } \\
\text { de exploración y explotación de } \\
\text { mina, elaboración de cartografía, } \\
\text { selección de muestras para realizar } \\
\text { análisis y asistencia a la dirección } \\
\text { en documentación de la empresa }\end{array}$ & No contestó \\
\hline $\begin{array}{l}\text { Instituto Nacional de } \\
\text { Estadística, Geografía e } \\
\text { Informática }\end{array}$ & Puebla, Puebla & Técnico & $\begin{array}{l}\text { Aplicación de geoprocesos a } \\
\text { través de índices normalizados } \\
\text { mediante clasificación de } \\
\text { imágenes de satélite de sensores } \\
\text { remotos, identificación de rasgos, } \\
\text { digitalización de polígonos } \\
\text { de crecimiento, análisis de } \\
\text { información geográfica, manejo } \\
\text { de sistemas de información } \\
\text { geográfica aplicado a detección } \\
\text { de cambios, revisión de estación } \\
\text { fija OAX2 }\end{array}$ & No contestó \\
\hline Grupo ATACSA & Querétaro, Querétaro & Jefe de área & $\begin{array}{l}\text { Revisión de grupos y supervisión } \\
\text { de cumplimiento de normas de } \\
\text { seguridad de mina }\end{array}$ & No contestó \\
\hline Empresa privada & Ciudad de México & Empleado & $\begin{array}{l}\text { Cartografía y sistemas de } \\
\text { información geográfica }\end{array}$ & No contestó \\
\hline
\end{tabular}

Fuente: elaboración propia, 2018.

\section{Anexo}

\section{BY-NC-ND}

